\title{
The Effect of Cultural-Social Programs on Pensioners' Satisfaction in Social Security Organization in Iran
}

\author{
Siamak Asgari ${ }^{1}$ \\ ${ }^{1}$ Department of management, North Tehran Branch, Islamic Azad University, Tehran, Iran \\ Correspondence: Siamak Asgari, Department of management, North Tehran Branch, Islamic Azad University, \\ Tehran, Iran. E-mail: assiamak636@gmail.com
}

Received: December 30, 2019

Accepted: March 12, 2020

Online Published: April 8, 2020

doi:10.5539/ijbm.v15n5p1

URL: https://doi.org/10.5539/ijbm.v15n5p1

\begin{abstract}
The economic development of the country has a direct relationship with the role of the social security organization in the fair distribution of wealth and the creation of the processes supporting government programs. For the insurer organizations, and especially the social security organization, to maintain the satisfaction of its customers as the main capital of this organization, they should increase the quality of their services. The purpose of the present study is to investigate the effect of the quality of socio-cultural projects and programs on improving the level of satisfaction of pensioners. The purpose of this study is applied and has a descriptive-survey method. The statistical population includes all pensioners of social security organization in Golpayegan city. With the help of convenience sampling, 384 pensioners of this city were surveyed. In order to analyze the data, mean test of a society, Pearson correlation and linear regression were used. The results showed that the quality of the educational programs provided to the pensioners of the Social Security Organization is satisfactory. However, the quality of social and cultural programs provided to pensioners of the Social Security Organization was not satisfactory. Finally, it was found that the quality of the educational, social and cultural programs offered affected the satisfaction of the social security organizations.
\end{abstract}

Keywords: service quality, socio-cultural programs, pensioner, social security organization

\section{Introduction}

Today, many organizations define value creation of their organization in terms of customer satisfaction. Strategic programs, mission statements and organizational policies show this fact. As competition intensifies and customers' expectations increase, it is necessary to achieve higher levels of customer satisfaction for the survival of the organization. Since customers play the main role in the process of organizational activities and affect the organization's fate through their thoughts and policies, it is necessary to understand their obvious needs and predict, determine and direct latent needs of customers and design and implement programs and provide services to meet these needs (Tseng \& Su, 2013). Therefore, any plan and design to improve organization must be based on expectations and needs of customers. In addition, to provide a clear image of customers' satisfaction, it is necessary to measure the satisfaction of internal customers (employees) and external customers (clients) from the above mentioned factors by identifying factors affecting their satisfaction (Tsoukatos \& Rand, 2007).

One of the most important service organizations that plays an important role in the economy of countries is the social security organization, so that economic development of the country has a direct relationship with the role of the social security organization to distribute wealth fairly and create processes that support the government's programs. Pensioners are an important group of external customers of the social security organization and attracting their satisfaction is very important for the organization (Forouzan, 2012). Basically, social welfare is one of the main programs of the government to provide citizens' happiness and according to its role and effect on economic and social development, it is the main aims of social policy and social welfare indicators are usually one of the indicators of the country's development. Rate of covering medical insurance and pensioning are the most important indicators of social welfare and to achieve the qualitative development of these indicators, a dynamic tool known as social insurance and a safe pathway known as "social security" are necessary to make it possible to achieve the social welfare (Nasrollahi, 2011).

Therefore, the stronger the foundations of social insurance and social security, the quicker the achievement to social welfare will be. It must be mentioned that the most important mission of social security systems in 
different countries and in the framework of human rights global statement is to achieve social justice, supply a suitable living, ensure it for people, provide a suitable context to realize growth and provide stable development, create social and mental calmness, and create economic, social, political and cultural security to provide the contexts of human growth. In the principle 29 of the constitution, social security is the most important lever of social justice and is a necessary right to protect human dignity and the right of social security belongs to all people and governments are required to provide this right for every one.

\subsection{Research Problem}

In Iran, supports of the social security system are provided in two frameworks including participatory system (including insurance strategies that are based on employment and paying the premium) and non-participatory system (including supportive strategies that are based on social unity and public revenues) and social security organization is one of the most important social institutions active as participatory system and is the most central insurance organization of Iran that provides services in the pensioning and treatment section from 1975 based on specific regulations (Azami, 2009). Such these services and their social supports are increasingly important because the number of old people in Iran was less than 1.2 million people in 1956 and has achieved above 7.4 million people in 2016. However, the country's population has quadrupled during this period. It shows that the speed of increasing old people has doubled during the past 60 years. Also, the number of old people of the country has grown 9 times in urban regions and has doubled in rural regions. In fact, the growth of the elderly population is more than the growth of the country's total population. It is predicted that to 2050 , about $20 \%$ of the country's population are the elderly (Baladi Mousavi, 2017).

These changes in population are the most important challenge that the social security organization will face in future and it will have a heavy responsibility in addition to duties due to the increase in the elderly and its responsibility to pay for the pensioners and their treatment. Anyway, what makes paying attention to pensioners important is the fact that the face of pensioners is a mirror that the active youth of the society see their future face in it. If pensioners don't have suitable conditions, they will get frustrated in future. Therefore, attempt to meet the needs of this class of society is an attempt for society's health. On the other hand, paying attention to the living-emotional needs of the pensioning period will directly affect the efficiency expected from the employed people and the motive of the employed people can be increased and their efficiency can be promoted by examining the needs of this class of people and factors affecting the satisfaction of pensioners and knowing these factors. At present, more than 1.5 million pensioners are covered by the social security organization and their growing population has made it more important to pay attention to this class of the society according to the issue of aging in the population of the country in future. In addition, approving the rules of pre-mature pensioning has increased the number of pensioners of the social security organization and has created problems and challenges for pensioners of this organization.

As pensioners increase, their social role and importance in the society have increased more than any other time. So, according to the increase in the number of pensioners of the organization, it is more necessary to pay attention to the status of this group in terms of planning and providing facilities to solve their problems and improve their living status. Social-cultural programs are one of the actions taken by the social security organization to promote the satisfaction of pensioners. These programs that are applied in three innovative, developmental and current sections include producing and distributing information animations, providing training insurance CDs, sending pensioner and their families to Mashhad, appreciation of superior employers, celebration of family day and appreciating the pensioners, distributing information brochures with an emphasis on health such as diabetes, hypertension, alzheimer, nutritional recommendations for pensioners, traditional medicine, and sport for pensioners, training workshops about regulations of insurance for employers and workers, participating in national media and explaining insurance rules, responding to public questions and holding sport-cultural olympiads for pensioners.

In fact, to support the social-cultural programs, this organization assigns a budget each year to implement different social-cultural programs for employers, the insured and pensioners. On the other hand, since the social security organization has a heavy social responsibility, modifying the behavior of colleagues and beneficiaries is the current needs of this organization. For this purpose, improving the behavior of the staff toward the clients and beneficiaries, especially pensioners, is one of the most important priorities of the social security organization in the cultural field. In sum, culture creation and promotion of public awareness, effective interaction with social partners and improving trust and increasing satisfaction of beneficiaries, especially pensioners, are three social-cultural policies of the social security organization. For this purpose, special attention is given to the cultural-social field in strategic program of this organization. 


\subsection{Research Question and Objective}

According to the documents and capacities, the social security organization needs a study on planning in the cultural-social field for audience of this organization, especially pensioners and needs to act accordingly, because the performance of this organization not only affects the public culture of the country, but this organization is also affected by social-cultural space. According to what is mentioned above, the main question of this research is what is the expectation of the pensioners of the social security organization in the cultural social field and how much they are satisfied of the services and activities performed to meet their needs, especially in social cultural field. Therefore, the present study, aims to to study the satisfaction of the pensioners of the organization of the social-cultural plans and programs and factors affecting it by doing a descriptive study and using the survey method.

\section{Literature Review and Hypotheses}

Superior service quality is known as one of the key issues to attract customers' satisfaction. Service quality and customer satisfaction are entangled with each other. Since customers' satisfaction is one of the important indicators of organizations' marketing, service quality has attracted the attention of researchers very much. Service quality is a kind of long term attitude. Today, an important part of GDP of developed countries is related to service sector and for this reason, increasing the quality and creating satisfaction in this sector are more important than the product production sector. It should be mentioned that in service industries like insurance, the perceived service quality is the basic factor to determine customer's loyalty and satisfaction. For example, the communication system between insurance company and client/customer is a strategy followed by insurance companies to promote the satisfaction of those who get service. In fact, facilities and channels of comfortable communication between the insurer and the insured, easy access to sales network, easy access to channels of damage payment and other services of insurance companies are factors affecting the quality of the insurance services. In addition, responsiveness to customers in all stages of service provision must be accompanied by respect and suitable behavior of the staff of the insurance company. This is a factor affecting the quality of insurance services and an indicator of customers' satisfaction. Being friendly and respecting the insured results in their satisfaction even if their need is not satisfied.

As the largest insurance organization, the social security organization provides a wide range of cultural, social and educational services to those who are insured and pensioners. In a research, the study of the performance of the social security organization and its role in the increase in satisfaction and social welfare, Mah (2010) stated in a case study on pensioners of Khomeinishahr branch that the level of social welfare is one of the factors of growth and development of the countries. So, the researcher tried to study the performance of the social security organization and its role in increasing satisfaction and social welfare of pensioners in Khomeinishahr branch and collected the required data through questionnaire with the sample size 387. The results showed that the higher the awareness of insurance regulations, the more the satisfaction will be, and there is a significant relation between the type of insurance and pension, and the lower the pensioning age, the higher the life expectancy and the higher the satisfaction of the pension.

Futurology of the organization shows according to the country's perspective in 2025 and creation of welfare government according to wealth distribution that although the organization was a pioneer organization in social welfare, but in near future, it will experience serious problems in terms of sources and consumption. Since the economic infrastructure of the organization is more from premiums paid by the insured, the organization will face lack of liquidity at present due to factors such as decrease in time of receiving the premium, decrease in pensioning age and increase in life expectancy and increase in period of receiving pensions, etc. However, the number of the insured and pensioners is increasing daily and it was proposed that the government is committed to the provision of treatment and health of the whole country in order that the premium decreases $9 \%$ and reaches $18 \%$ and also the average value in the period of pensioning increases from 2 years to 4 years. According to what is mentioned above and literature review, three hypotheses of the present study are proposed as follows:

H1. The quality of the educational programs provided for pensioners of the social security organization is satisfactory.

H2. The quality of the cultural programs provided for pensioners of the social security organization is satisfactory.

H3. The quality of the social programs provided for pensioners of the social security organization is satisfactory.

Hosseini Abri (2013) studied the economic, social and individual problems of pensioners of the social security organization in Kokilouyeh Boyer Ahmad (Yasouj, Dehdash and Gachsaran) and offered scientific applied 
approaches to solve their problems. In a case study in the branch 13 of the Social Security Organization at the west of Tehran, Forouzan (2012) found that as social base increases due to higher education, enough income and type of occupation, individual satisfaction increases and so the individual will be calmer and enjoy his life. On the other hand, improvement of economic conditions plays an important role in the satisfaction of individuals, education also affects satisfaction of pensioners of welfare services and the higher the job position of the pensioner, the higher his satisfaction of the services will be. Nasrollahi (2011) identified the features and the most important economic, social and cultural and executive problems of pensioners of the social security organization in Tehran and offered solutions such as the increase in financial aids to low-income pensioners, revising the benefits paid to the pensioners, modifying service provision and service provision processes, following justice in financial payments such as loans, training the staff about their interaction with pensioners, solving their problems quickly, quick response to their problems according to their position.

Azami (2009) studied one of the social issues with the title "the study of the satisfaction of the unemployment insurance and its factors" (the unemployed covered by the social security organization in Tehran). The population of the research included individuals referring to the centers of employment services in Tehran and the sample size was 385. The results of the combination of items of satisfaction of unemployment insurance among the respondents showed that about $55 \%$ of the respondents are satisfied of the services of unemployment insurance at an average level. But about $22 \%$ were less satisfied and $23 \%$ were highly satisfied. In a research, "the perceived service quality, repeated use of healthcare services and inpatient satisfaction in emerging economy", Trivedi and Jagani (2018) studied how different demographic variables and repeated use of services of a physician or similar hospital form perceptions of the quality of healthcare services and their satisfaction among inpatients in private hospitals in emerging economies. The questionnaire was formulated by the researcher for inpatients in Indian and Gojrat languages and was distributed among 708 inpatients in 18 private clinic in the west of India. The results indicated that the experience of the hospital manager, physicians, nursing staff, physical environment and pharmacy of the hospital are important predictors of the inpatients satisfaction. Physical environment was significantly related to satisfaction among female inpatients.

Mattah et al. (2018) studied the indicators of service quality among graduating students of a higher education institution in Ghana. The identified indicators of service quality were ranked and the level of satisfaction of students was determined. A questionnaire was distributed among 482 graduating students and $t$ and $z$-tests were used to compare the average grade and perceptions of respondents about different variables. The results indicated three service quality indicators including the quality of facilities and university services, the quality of lectures and the quality of university programs. The graduating students were satisfied of services, lectures and programs. However, they were not satisfied of the service qualities. Silvestri et al. (2017) offered empirical evidence about service quality dimensions (technical, functional and mental image of the company) and their relation in thermal tourism. The results of the regression analysis showed that service quality dimensions (technical, functional and mental image of the company) affect the customer satisfaction in thermal tourism. In addition, when mental image of the company was analyzed, the communication quality was related to capabilities, abilities, reliability and getting access to the staff. Finally, the functional service quality and mental image of the company had a stronger effect on customer satisfaction than technical service quality.

Khoo et al. (2017) studied the relations between service quality, students' satisfaction and behavioral intentions in private education sector using a case study in Singapore. Initial data were gathered from 324 students in two private education institutions in Singapore. The results showed that the perceived service quality was positively related to satisfaction, the perceived service quality has a positive relationship with desirable behavioral intentions and relationships between the perceived service quality and loyalty and more payment for a service are modulated by satisfaction. In a research, service quality and satisfaction in the banking sector, Fatima and Razzaque (2014) studied antecedent and intermediate effects of core, relational and tangible service quality on compatibility and satisfaction of customers. 212 bank customers were surveyed and data were analyzed using structural equations modeling. Findings showed that relational service quality has an antecedent and intermediate effect on satisfaction-compatibility relation. Core service quality was the only antecedent affecting the compatibility, while no relationship was significant for tangible service quality. As Fatima and Razzaque (2014) suggest, the quality of different services provided by the organization affects the satisfaction of the clients. Hence, it is expected that the quality of educational, cultural and social services of the social security organization provided for pensioners affects their satisfaction. Accordingly, the forth hypothesis is proposed:

H4. The quality of the educational, cultural and social programs of the social security organization affects the satisfaction of the pensioners. 


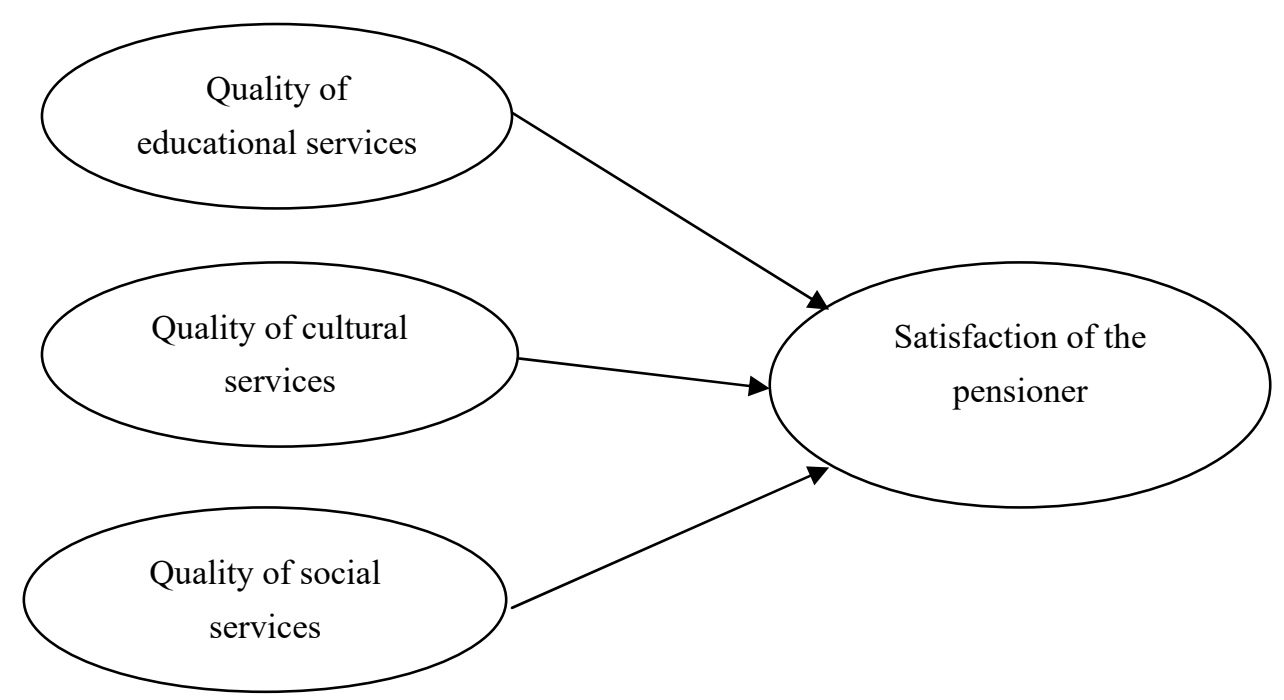

Figure 1. The conceptual model of the research

\section{Method}

Since the purpose of the present research is to examine the effect of the quality of social-cultural programs of the social security organization to promote the satisfaction of the pensioners, this research is an applied research. Since the different documents, evidence, articles, theses and books are studied in this research and field method and questionnaire are used and its aim is to study the effect of social-cultural programs of the social security organization to promote the satisfaction of the pensioners and this aim is met by using opinions of pensioners of the social security organization, the present research is a descriptive-survey research.

\subsection{Sampling Procedures}

The population of the research includes all pensioners of the social security organization in Golpaygan, Isfahan. Since in this study, the volume of the population is infinite, the sample size was taken as 384 using Krejcie and Morgan table. To collect the required data, pensioners of the branch Golpayegan of the social security organization were sampled by going there. In fact, the sampling method was convenience sampling.

\subsection{Participant Characteristics}

In this section, data of general characteristics of the respondents are studied and described such as gender, age, education and type of pension. In the sample of the study, the total number of respondents is 384 , among which $68.5 \%$ are males and $31.5 \%$ are females. $10.2 \%$ of the respondents are less than 30 years old, $28.1 \%$ are between 31 to 40 years old, $16.9 \%$ are between 41 to 50 years and $25.8 \%$ are between 51 to 60 years, and $19 \%$ are more than 60 years old. $52.1 \%$ of the respondents had associate's degree or lower, $29.7 \%$ had bachelor's degree, and $18.2 \%$ had master's degree or higher. Finally, $13.3 \%$ of the respondents received pension of survivors, $75 \%$ received pension of retirement and $11.7 \%$ received pension of disability.

Table 1. Characteristics of the respondents

\begin{tabular}{|c|c|c|c|}
\hline Variable & Dimension & Frequency & Frequency \\
\hline \multirow[t]{4}{*}{ Gender } & Male & 263 & $68.5 \%$ \\
\hline & Female & 121 & $31.5 \%$ \\
\hline & 30 years old and less & 39 & $10.2 \%$ \\
\hline & Between 31 to 40 years old & 108 & $28.1 \%$ \\
\hline \multirow[t]{4}{*}{ Age } & Between 41 to 50 years old & 65 & $16.9 \%$ \\
\hline & Between 51 to 60 years old & 99 & $25.8 \%$ \\
\hline & More than 60 years old & 73 & $19.0 \%$ \\
\hline & Associate's degree and lower & 200 & $52.1 \%$ \\
\hline \multirow[t]{3}{*}{ Education } & Bachelor's degree & 114 & $29.7 \%$ \\
\hline & Master's degree and higher & 70 & $18.2 \%$ \\
\hline & Pension of survivors & 51 & $13.3 \%$ \\
\hline \multirow[t]{2}{*}{ Type of pension } & Pension of retirement & 288 & $75 \%$ \\
\hline & Pension of disability & 45 & $11.7 \%$ \\
\hline
\end{tabular}




\subsection{Instrument, Validity and Reliability}

To gather data related to responding to the questions, field method using questionnaire is used in this research. The first section included questions about characteristics of pensioners such as their education, type of pension, age and gender. The second section included questions about the quality of educational, cultural and social services and also satisfaction of the performance of the social security organization. To measure variables of the research, five point Likert spectrum was used. This spectrum is composed of five choices and each choice is analyzed using a special code from 1 to 5 .

Table 2. Characteristics of the questionnaire of the research

\begin{tabular}{llll}
\hline Variable & $\begin{array}{l}\text { Questions related to variable in } \\
\text { questionnaire }\end{array}$ & $\begin{array}{l}\text { Questionnaires used to provide } \\
\text { any section }\end{array}$ & $\begin{array}{l}\text { Cronbach's } \\
\text { alpha }\end{array}$ \\
\hline Quality of educational services & $1-7$ & Fatima\&Razzaque $(2014)$ & 0.874 \\
Quality of cultural services & $8-12$ & Fatima\&Razzaque $(2014)$ & 0.822 \\
Quality of social services & $13-17$ & Fatima\&Razzaque $(2014)$ & 0.854 \\
Satisfaction of the pensioner & $18-25$ & Williams (2014) & 0.795 \\
\hline
\end{tabular}

To determine the face validity, the questionnaire was given to two academic experts and some experts of the social security organization and their opinions were asked about the questions of the research. After applying their opinions and modifying the final questionnaire, it was formulated and used. To determine the reliability of the questionnaire, Cronbach's alpha was used. To test it, the questionnaire was distributed among 50 respondents and their data were analyzed. The questionnaire of the research can be divided into two sections; the first section is related to the quality of educational, cultural and social services. Cronbach's alpha of the quality of educational services was 0.874 , that of cultural service quality was 0.822 and that of social service quality was 0.854 . The second section is related to satisfaction of pensioners of the services provided by the social security organization. The Cronbach's alpha of this section was 0.795 . Since the Cronbach's alphas of all variables are above 0.7, the questionnaire is reliable.

\subsection{Analytical Process}

To analyze data, SPSS software was used for statistical tests such as the mean test of a society, correlation test and multiple regression analysis.

\section{Results}

To test the first minor hypothesis, the mean test of a society was used. The following table shows that the mean of answering the questions of the first hypothesis is $3.24 \%$, t-value is 2.076 and significance is 0.043 . Since this value is less than alpha's value at the level of error 0.05 , the hypothesis of the research is supported $(\mathrm{P}=0.000<0.05)$. In other words, the quality of the educational programs offered to pensioners of the social security organization is satisfactory. The mean of answering the questions of the second minor hypothesis is 2.86 , $\mathrm{t}$-value is -0.989 and significance is 0.328 . Since this value is more than alpha's value at the level of error 0.05 , the second hypothesis is rejected $(\mathrm{P}=0.328>0.05)$. In other words, the quality of the cultural programs offered to pensioners of the social security organization is not satisfactory. In addition, the mean of answering the questions of the third hypothesis is 3.00 , t-value is 0.000 and significance is 1 . Since this value is more than alpha's value at the level of error 0.05 , the hypothesis of the research is rejected $(\mathrm{P}=1.00>0.05)$. In other words, the quality of the social programs offered to pensioners of the social security organization is not satisfactory.

Table 3. The test results of minor hypotheses using the mean test of a society

\begin{tabular}{|c|c|c|c|c|c|c|c|}
\hline & Mean & $\begin{array}{l}\text { Standard } \\
\text { deviation }\end{array}$ & $\begin{array}{l}\text { Standard error } \\
\text { mean }\end{array}$ & $\mathrm{t}$ & Significance & $\begin{array}{l}\text { Lowest } \\
\text { limit }\end{array}$ & $\begin{array}{l}\text { Highest } \\
\text { limit }\end{array}$ \\
\hline $\begin{array}{l}\text { Quality of educational } \\
\text { programs }\end{array}$ & 3.2362 & 0.7962 & 0.1137 & 2.076 & 0.043 & 0.0074 & 0.4649 \\
\hline Quality of cultural programs & 2.8653 & 0.9534 & 0.1362 & -0.989 & 0.328 & -0.4085 & 0.1392 \\
\hline Quality of social programs & 3.00 & 0.9363 & 0.1337 & 0.00 & 1.00 & -0.2689 & 0.2689 \\
\hline
\end{tabular}

To test the fourth minor hypothesis, Pearson correlation coefficient and simple linear regression are used. The following table shows the coefficients of the correlation of the variables "the quality of educational, cultural and 
social programs of the social security organization" with pensioners' satisfaction. It is observed that in the above test, significance is less than the level of error ( $\mathrm{p}$-value $=0.000<0.05$ ). Therefore, $\mathrm{H} 0$ is rejected and hypothesis of the research is supported. Hence, there is a direct relationship between the quality of educational, cultural and social programs of the social security organization and the pensioners' satisfaction.

Table 4. The test results of the fourth minor hypothesis using Pearson correlation test

\begin{tabular}{lll}
\hline & & Pensioners' satisfaction \\
\hline \multirow{2}{*}{ Quality of educational programs } & Pearson correlation & 0.583 \\
& Two-tailed significance & 0.000 \\
Quality of cultural programs & Pearson correlation & 0.588 \\
& Two-tailed significance & 0.000 \\
\multirow{2}{*}{ Quality of social programs } & Pearson correlation & 0.625 \\
& Two-tailed significance & 0.000 \\
\hline
\end{tabular}

The following table shows that the (independent) variables predicting the quality of the educational, cultural and social programs of the social security organization explain 0.463 of the changes in pensioners' satisfaction. According to the significance test, it is observed that the variance explained is significant at the level of error 0.05 .

Table 5. Simple linear regression between the quality of educational, cultural and social programs and pensioners' satisfaction

\begin{tabular}{ccccc}
\hline Model & $\begin{array}{c}\text { Coefficient of } \\
\text { determination }\end{array}$ & $\begin{array}{c}\text { Modulated determination } \\
\text { coefficient }\end{array}$ & F & Significance \\
1 & 0.463 & 0.427 & 12.944 & 0.000 \\
\hline
\end{tabular}

As it is observed, the significance level of the variables including the quality of educational, cultural and social programs of the social security organization is significant at the level of confidence $95 \%$. In table $13.4, \mathrm{~B}$ coefficient is used to predict the changes that is $0.225,0.240$ and 0.283 for the quality of educational, cultural and social programs of the social security organization, respectively.

Table 6. Linear regression coefficients between the quality of educational, cultural and social programs and pensioners' satisfaction

\begin{tabular}{llllll}
\hline & \multicolumn{2}{l}{ Non-standard coefficients } & $\begin{array}{l}\text { Standard } \\
\text { coefficients }\end{array}$ & $\mathrm{t}$ & Sig. \\
& $\mathrm{B}$ & $\begin{array}{l}\text { Standard } \\
\text { deviation }\end{array}$ & Beta & & \\
\hline Constant & 2.227 & 0.287 & - & 7.749 & 0.000 \\
Quality of social programs & 0.283 & 0.119 & 0.363 & 2.384 & 0.021 \\
Quality of cultural programs & 0.240 & 0.108 & 0.289 & 2.122 & 0.032 \\
Quality of educational programs & 0.225 & 0.095 & 0.264 & 2.002 & 0.041 \\
\hline
\end{tabular}

To test the major hypothesis, the mean of the quality of cultural, educational and social programs of the social security organization was considered as the indicator of the quality of cultural-social programs. The following table shows the coefficient of the correlation of the variables including the quality of cultural-social programs and pensioners' satisfaction. It is observed that in the above test, level of significance was less than the error level ( $\mathrm{p}$-value $=0.000<0.05$ ). Therefore, $\mathrm{H} 0$ is rejected and hypothesis of the research is supported. Hence, there is a direct relationship between the quality of social-cultural programs and pensioners' satisfaction.

Table 7. the test results of the major hypothesis using Pearson correlation test

\begin{tabular}{ccc}
\hline & & Pensioners' satisfaction \\
\hline Quality of cultural-social programs & Pearson correlation & 0.673 \\
& Two-tailed significance & 0.000 \\
\hline
\end{tabular}


The following table shows that the (independent) variable predicting the quality of the cultural and social programs explains 0.453 of the changes in pensioners' satisfaction. According to the significance test, it is observed that the variance explained is significant at the level of error 0.05 .

Table 8. Simple linear regression between the quality of cultural and social programs and pensioners' satisfaction

\begin{tabular}{llllll}
\hline Model & $\begin{array}{l}\text { Coefficient } \\
\text { determination }\end{array}$ & of & $\begin{array}{l}\text { Modulated } \\
\text { coefficient }\end{array}$ & determination & F \\
\hline 1 & 0.453 & 0.441 & 38.876 & 0.000 \\
\hline
\end{tabular}

In the following table, B coefficient is used to predict the changes that is 0.525 . In other words, for one unit of change in the independent variable i.e. quality of cultural-social programs, the dependent variable i.e. pensioners' satisfaction will change as 0.308 .

Table 9. Linear regression coefficients between the quality of cultural-social programs and pensioners' satisfaction

\begin{tabular}{|c|c|c|c|c|c|}
\hline & \multicolumn{2}{|c|}{$\begin{array}{l}\text { Non-standard } \\
\text { coefficients }\end{array}$} & \multirow{2}{*}{$\begin{array}{l}\text { Standard } \\
\text { coefficients } \\
\text { Beta }\end{array}$} & \multirow{2}{*}{$\mathrm{t}$} & \multirow{2}{*}{ Sig. } \\
\hline & B & $\begin{array}{l}\text { Standard } \\
\text { deviation }\end{array}$ & & & \\
\hline Constant & 2.325 & 0.264 & - & 8.817 & 0.000 \\
\hline Quality of cultural-social programs & 0.525 & 0.084 & 0.673 & 6.235 & 0.000 \\
\hline
\end{tabular}

\section{Discussion and Implications}

Generally, the purpose of the research is to study the quality of social-cultural programs of the social security organization to promote pensioners' satisfaction. The results showed that the quality of educational programs provided for pensioners of the social security organization is satisfactory, but the quality of social-cultural programs provided for pensioners of the social security organization is not satisfactory. Also, the results showed that the quality of educational, cultural and social programs affects the pensioners' satisfaction. These findings are consistent with those of the researchers such as Trivedi and Jagani (2018), Mattah et al. (2018) Silvestri et al. (2017), Khoo et al. (2017) and Fatima and Razzaque (2014) on the effect of service quality on customers' satisfaction. According to the results, suggestions are given to the managers of the social security organization in Golpayegan. The results showed that the quality of educational services of the social security organization is acceptable. However, to improve the quality of the educational services, suggestions can be offered to managers of the organization.

The organization must inform the pensioners on the rights and tasks determined in the regulations at an acceptable level to increase their awareness of their rights. In addition, the organization must provide conditions of mutual cooperation to solve the problems of the pensioners. Mutual interaction with pensioners helps identify their problems and plan for their solution. Moreover, the organization must provide suitable trainings to create a healthy lifestyle for pensioners. This issue is important because pensioners need to modify their current lifestyle and optimize it due to their age. On the other hand, providing educational brochures and catalogues, the organization can help promote the quality of their life. Also, another tool that can be helpful to train and promote the pensioners' awareness is to release and distribute magazines of the organization to know their services better.

According to the findings, the quality of social services of the social security organization is not suitable. Therefore, it is suggested that the organization must improve clinical and hospital services, define the necessary standards to promote the quality of rehabilitation services and diagnostic and pharmaceutical services, develop the insurance in the centers partnering with the organization, do medical examinations by physicians and professionals of the organization timely, help establish pensioners community as cooperative companies when protecting from the dignity of those who get services, and also modify the level of pension of pensioners to meet their material needs at the maximum level.

The results showed that pensioners are not satisfied of the quality of cultural services. Accordingly, it is suggested that the organization must send the pensioners to pilgrimage trips to make them satisfied. Another action that must be taken by the organization is to provide consultancy services for pensioners. On the other hand, 
the organization must spread the culture of insurance and social security among pensioners and their families. Also, the organization must try to know the views of the insured and pensioners and ask for their feedback. Obviously, in these conditions, one can expect that their problems are solved and their satisfaction is increased. Finally, the organization must try to develop services and programs of the pensioners. According to the results, the quality of the educational, cultural and social services of the social security organization affects their satisfaction. Hence, it is suggested that the organization must increase the speed of the services provided for pensioners, respond to their questions as much as possible, promote the level of knowledge and profession of its staff on the required services by training them, improve the quality of the physical environment where services are provided for pensioners, deal with complaints of pensioners and emphasize suitable attitude toward pensioners in order to promote their satisfaction.

\section{Limitations and Future Work}

The present research had limitations. Findings of the present research are limited to temporal and spatial dimensions. It must be noted that this research is conducted in Golpayegan. So, before generalizing the findings to other cities and branches of the social security organization, similar researches must be performed in other places. Lack of Persian sources was another limitation to complete the literature review, because there is no other research in Iran that has examined the quality of the services of the social security organization in terms of social, educational and cultural dimensions. According to the experiences gained during doing the research, future researchers are recommended to do research on the following subjects.

In this research, the opinions of the pensioners were gathered on the quality of (educational, cultural and social) services and pensioners' satisfaction by relying on the questionnaire. It is suggested to evaluate and analyze the opinions of pensioners on the quality of different services provided by the organization perfectly as organized interviews in future researches. In this research, only the quality of face to face services of the organization was focused and its relation with pensioners' satisfaction was evaluated. Nevertheless, some services of the organization are electronic. So it is suggested that in future researches, the effect of the quality of electronic services of the organization is examined on pensioners' satisfaction. This research was conducted in the social security organization in Golpayegan. To increase the generalizability of the results, similar researches must be performed in other branches of the organization in other cities.

\section{References}

Azami, H. (2009). The study of the satisfaction of the unemployment insurance and its factors (the unemployed covered by the social security organization in Tehran). Master thesis, Faculty of Social Sciences, Allame Tabatabaei University, Tehran, Iran.

Baladi Mousavi, S. (2017). The status of the elderly of the country, Report of the statistical center of Iran.

Fatima, J. K. \& Razzaque, M. A. (2014). Service quality and satisfaction in the banking sector, International $\begin{array}{lllll}\text { Journal of Quality \& Reliability } & \text { Management, } & 31(4), & \text { 367-379. }\end{array}$ https://doi.org/10.1108/IJQRM-02-2013-0031

Forouzan, M. (2012). Study of satisfaction of the pensioners of the social security organization of the welfare services provided and social factors affecting it, a study in the branch 13 of the social security organization at the west of Tehran. Master thesis, Allame Tabatabaei University, Tehran, Iran.

Hosseini Abri, S. H. (2013). The economic, social and individual status of pensioners in Kokilouyeh Boyer Ahmad. Social Security Organization Report.

Khoo, S., Ha, H., \& McGregor, S. L. T. (2017). Service quality and student/customer satisfaction in the private tertiary education sector in Singapore, International Journal of Educational Management, 31(4), 430-444. https://doi.org/10.1108/IJEM-09-2015-0121

Mah, A. (2010). The study of the performance of the social security organization and its role in the increase in satisfaction and social welfare, (case of study, pensioners of Khomeinishahr). Master thesis, Isfahan University, faculty of literature and humanities, Isfahan, Iran.

Mattah, P. A. D., Kwarteng, A. J. \& Mensah, J. (2018). Indicators of service quality and satisfaction among graduating students of a higher education institution (HEI) in Ghana. Higher Education Evaluation and Development, 12(1), 36-52. https://doi.org/10.1108/HEED-10-2017-0006

Nasrollahi, S. (2011). The study of the economic and social status of the retired and disabled pensioners of the organization in Tehran, Research plan of Almizan Institute, Tehran, Iran.

Silvestri, C., Aquilani, B., \& Ruggieri, A. (2017). Service quality and customer satisfaction in thermal tourism. 
The TQM Journal, 29(1), 55-81. https://doi.org/10.1108/TQM-06-2015-0089

Trivedi, R., \& Jagani, K. (2018). Perceived service quality, repeat use of healthcare services and inpatient satisfaction in emerging economy: Empirical evidences from India. International Journal of $\begin{array}{llll}\text { Pharmaceutical } \quad \text { and } & \text { Healthcare 288-306. }\end{array}$ https://doi.org/10.1108/IJPHM-11-2017-0065.

Tseng, L. M. \& Su, W. P. (2013). Customer orientation, social consensus and insurance salespeople's tolerance of customer insurance frauds. International Journal of Bank Marketing, 31(1), 38-55. https://doi.org/10.1108/02652321311292047

Tsoukatos, E., \& Rand, G. K. (2007). Cultural influences on service quality and customer satisfaction: evidence from Greek insurance, Managing Service Quality: An International Journal, 17(4), 467-485. https://doi.org/10.1108/09604520710760571

Williams, P. (2014). Emotions and Consumer Behavior. Journal of Consumer Research, 40(5). 121-139. https://doi.org/10.1086/674429

\section{Copyrights}

Copyright for this article is retained by the author(s), with first publication rights granted to the journal.

This is an open-access article distributed under the terms and conditions of the Creative Commons Attribution license (http://creativecommons.org/licenses/by/4.0/). 